\title{
Review of creep modelling for predicting of long-term behavior of glued-laminated bamboo structures
}

\author{
Ngudiyono $^{1,2^{*}}$, Bambang Suhendro ${ }^{3}$, Ali Awaludin ${ }^{3}$, Andreas Triwiyono $^{3}$ \\ ${ }^{1} \mathrm{Ph} . \mathrm{D}$. Student at Department of Civil and Environmental Engineering, Gadjah Mada University, Yogyakarta, Indonesia \\ ${ }^{2}$ Department of Civil Engineering, Mataram University, Mataram, Indonesia \\ ${ }^{3}$ Department of Civil and Environmental Engineering, Gadjah Mada University, Yogyakarta, Indonesia
}

\begin{abstract}
Glued-laminated bamboo has been widely used to substitute timber as a building material. This material classified as a viscoelastic material because it exhibiting properties that are common to both solid and liquid. Under long-term constant loading, the glued-laminated bamboo structures will experience creep deformation. The mechanical, power law and finite element models are common methods that used to predict the creep for viscoelastic material, some of them have advantages and disadvantages. In this manuscript, modelling of long-term creep is reviewed. The fundamental concepts of creep modelling, the influence of variable load level, and humidity were discussed to develop for computational applications. By using FEA program, a subroutine has been developed by previous researchers to accommodate the effect of orthotropic properties. In the future, the subroutine will be used and developed for numerical creep analysis of glued-laminated bamboo.
\end{abstract}

Keywords: long-term behavior, creep, creep modelling, glued-laminated bamboo

\section{Introduction}

Glued-laminated bamboo has been widely used to substitute timber as a building material is a natural resource with many benefits. Because the gluedlaminated bamboo produced from bamboo the benefits including, for example, environmentally friendly, renewable and sustainable material, good mechanical properties and similar with timber [1-3]. Gluedlaminated bamboo is classified as a viscoelastic material because it exhibits properties that are common to both solid and liquid. Under long-term constant loading, the glued-laminated bamboo will be causing creep. The phenomenon of creep, especially in anisotropic or orthotropic materials is critical to structural design. For instance, creep on beams will cause $\mathrm{P}-\Delta$ effects, can possibly influence the serviceability of structures. Another problem due to creep is the ability to alter the material characteristics and mechanical properties of the structural elements, furthermore, will cause failure of a building structure [4-5]

There are many ways to predict the creep for viscoelastic material, some of them, including mechanical, power law and finite element model are common methods. In this manuscript, modelling of long-term creep is reviewed, and the fundamental concepts of creep modelling, the influence of variable load level, temperature and humidity will be discussed to develop for computational applications. By using finite element analysis (FEA) program, a subroutine has been developed by previous researchers to accommodate the effect of orthotropic properties. In the future, the subroutine will be used and developed for numerical creep analysis of glued-laminated bamboo.

\section{Viscoelastic Constitutive Equations}

The long-term deformation behavior of a material can be approximated by a linear viscoelastic theory. According to Hook's law, the constitutive equation of linear viscoelastic material is a function of time, written in matrix form in equation (1). The independent components matrix could be determined experimentally, by using uniaxial (compression, tension, shear) creep tests.

$$
\{\varepsilon(t)\}=[D(t)]\{\sigma\}
$$

For linear viscoelastic orthotropic material,

$$
\left\{\begin{array}{l}
\varepsilon_{x}(t) \\
\varepsilon_{y}(t) \\
\varepsilon_{z}(t) \\
\gamma_{x y}(t) \\
\gamma_{x z}(t) \\
\gamma_{y z}(t)
\end{array}\right\}=\left[\begin{array}{cccccccc}
\frac{1}{E_{1}(t)} & -\frac{v_{21}}{E_{2}(t)} & -\frac{v_{31}}{E_{3}(t)} & 0 & 0 & 0 & \\
-\frac{v_{12}}{E_{1}(t)} & \frac{1}{E_{2}(t)} & -\frac{v_{32}}{E_{3}(t)} & 0 & 0 & 0 & \\
-\frac{v_{13}}{E_{1}(t)} & -\frac{v_{23}}{E_{2}(t)} & \frac{1}{E_{3}(t)} & 0 & 0 & 0 & \\
0 & 0 & 0 & \frac{1}{2 \mathrm{G}_{23}(t)} & 0 & 0 \\
0 & 0 & 0 & 0 & \frac{1}{2 \mathrm{G}_{13}(t)} & 0 \\
0 & 0 & 0 & 0 & 0 & \frac{1}{2 \mathrm{G}_{12}(t)}
\end{array}\right]\left\{\begin{array}{l}
\sigma_{x} \\
\sigma_{y} \\
\sigma_{z} \\
\tau_{x y} \\
\tau_{x z} \\
\tau_{y z}
\end{array}\right\}
$$

For linear viscoelastic isotropic material,

$$
\left\{\begin{array}{l}
\varepsilon_{x}(t) \\
\varepsilon_{y}(t) \\
\varepsilon_{z}(t) \\
\gamma_{x y}(t) \\
\gamma_{x z}(t) \\
\gamma_{y z}(t)
\end{array}\right\}=\frac{1}{E(t)}\left[\begin{array}{cccccc}
1 & -v & -v & 0 & 0 & 0 \\
-v & 1 & -v & 0 & 0 & 0 \\
-v & -v & 1 & 0 & 0 & 0 \\
0 & 0 & 0 & 2(1+v) & 0 & 0 \\
0 & 0 & 0 & 0 & 2(1+v) & 0 \\
0 & 0 & 0 & 0 & 0 & 2(1+v)
\end{array}\right]\left\{\begin{array}{l}
\sigma_{x} \\
\sigma_{y} \\
\sigma_{z} \\
\tau_{x y} \\
\tau_{x z} \\
\tau_{y z}
\end{array}\right\}
$$

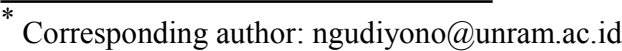




\section{Rheological Model}

In the rheological model, glued-laminated bamboo is assumed to behave as a viscoelastic material. In general, there are two forms used to represent the stress-straintime relationship of viscoelastic materials. They are known as the differential operator (mechanical model) and the integral representation (Boltzmann Superposition Principle Model). The differential operator model has been widely used for analysis since the mathematical processes required are reasonably simple. While, the integral representation is able to describe the time dependence more generally, however, it sometimes leads to difficult mathematics in stress analysis [6].

\subsection{Mechanical Model}

A mechanical model can be used to visualize the stressstrain relationship of the viscoelastic material due to the constant applied load within a certain time. In this model using linear elastic spring (Fig. 1 (a)) to idealize linear elastic solid and linear viscous dashpot (Fig. 1 (b)) to idealize viscous fluid. The constitutive equations in linear elastic solid and viscous fluid are shown in equation (2) and (3)

$$
\begin{aligned}
& \varepsilon=\frac{\sigma}{E} ; \\
& \dot{\varepsilon}=\frac{\sigma}{\eta}
\end{aligned}
$$

where $\varepsilon$ : strain; $\sigma:$ applied stress; E: Young Modulus; $\dot{\varepsilon}$ : rate of strain; $\eta$ : viscosity; $\mathrm{t}$ : time

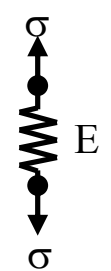

(a)

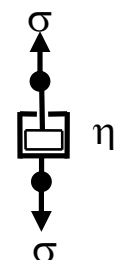

(b)
Fig. 1. (a) Linear elastic spring; (b) Linear dashpot [6]

Generally, the constitutive equation of viscoelastic linear material is presented in the form of the following differential equation [6]

$$
p_{0} \sigma+p_{1} \dot{\sigma}+p_{2} \ddot{\sigma}+\ldots . .+p_{n} \frac{\partial^{a} \sigma}{\partial t^{a}}=q_{0} \varepsilon+q_{1} \dot{\varepsilon}+q_{2} \dot{\varepsilon}+\ldots .+q_{n} \frac{\partial^{a} \varepsilon}{\partial t^{a}}
$$

where $\mathrm{p}_{0}, \mathrm{p} 1, \mathrm{p}_{2}, \ldots$. and $\mathrm{q}_{0}, \mathrm{q} 1, \mathrm{q}_{2}, \ldots$ are material constants, this constitutive equation of linear function to stress $(\sigma)$, strain $(\varepsilon)$ and derivative with time $\dot{\sigma}, \ddot{\sigma}, \ldots$. and $\dot{\varepsilon}, \ddot{\varepsilon}, \ldots$

There are several variations of the constitutive equation of viscoelastic linear material depending on combination number of the spring and the dashpot elements. For example, Maxwell and Kelvin model are adequate for qualitative and conceptual analysis, but generally poor for the quantitative representation of the behavior real materials. In order to improve the representation, a user needs to increase the number of elements by combining a number of springs and dashpots.

The simplest linear model that successfully describes the time-dependent behavior of viscoelastic material such as timber, bamboo, glued-laminated bamboo, etc, under constant humidity and temperature for a short period are four-element model or Burger model illustrated in Fig. 2, where the Maxwell and Kelvin model are connected in series. The constitutive equation can be derived by considering the strain response under constant applied loading. The total strain at the time it is obtained by summing the strain on four elements is given by the equation (5), where $\varepsilon$ : strain at time $t, \sigma_{0}$ : constant applied load, $\mathrm{E}_{\mathrm{M}}$ : elasticity of element spring Maxwell, $E_{K}$ : elasticity of element spring Kelvin, $\eta_{M}$ : viscosity of element dashpot Maxwell, $\eta_{K}$ :viscosity of element dashpot Kelvin. The first term on the right-hand side of the equation (5) represents instantaneous deformation, the second term describes delayed elasticity and the third term plastic flow component. So, the first term describes the elastic behavior while the combination of the second and third terms accounts for the viscoelastic or creep behavior. It should be noticed that the Burger model is valid only for primary and secondary creep behavior. The typical creep and relaxation of Burger model shown in Fig. 3.

$$
\varepsilon(t)=\frac{\sigma_{0}}{E_{M}}+\frac{\sigma_{0}}{\eta_{M}} t+\frac{\sigma_{0}}{E_{K}}\left(1-e^{-\left(E_{K} / \eta_{K}\right) t}\right)
$$

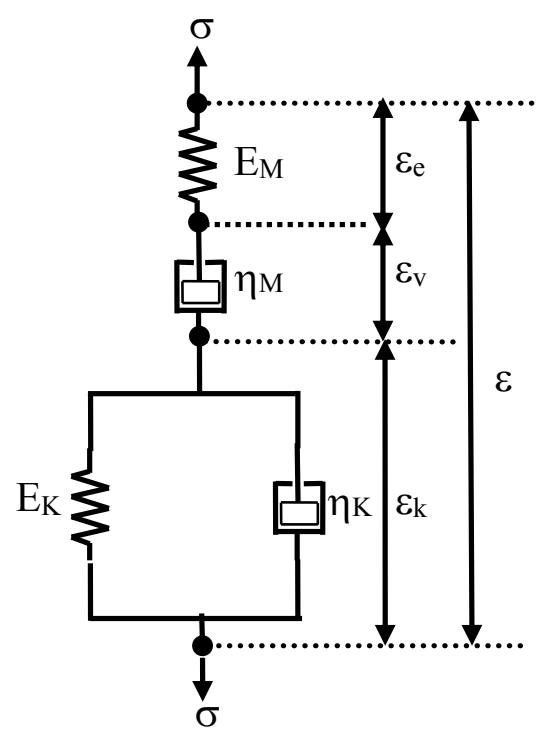

Fig. 2. Burger Model [6] 

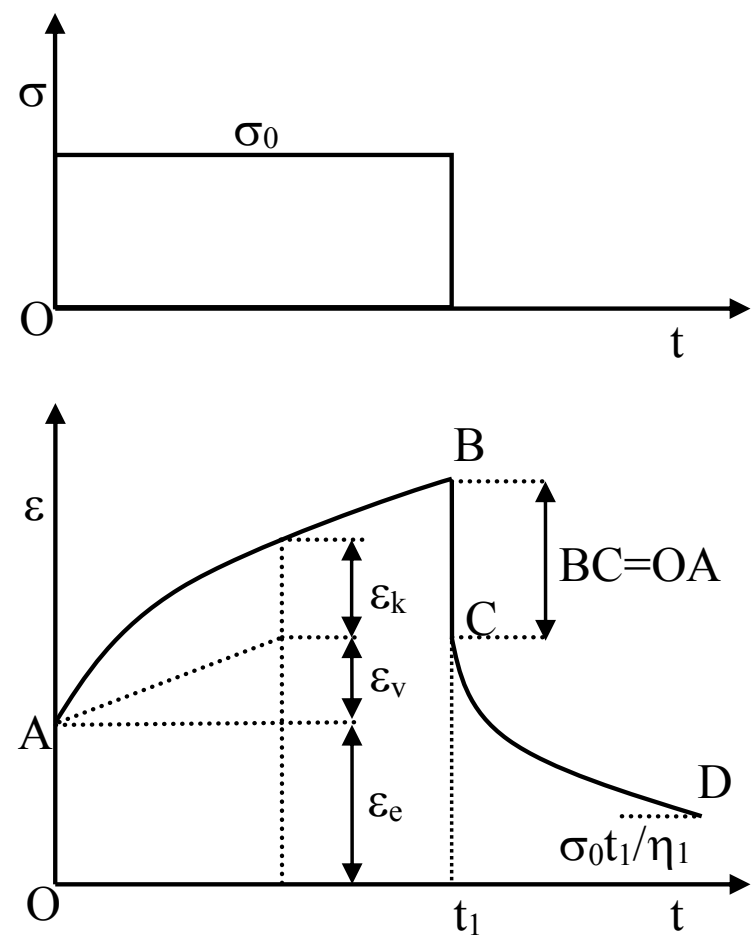

Fig. 3. Typical creep and Relaxation Burger Model [6]

For accommodate the effect of humidity conditions that often called mechano-sorptive, Leicester [7] proposed a rheological model for mechano-sorptive creep in wood beams during drying. In this model was a modified Maxwell model, where the dashpot element had been substituted by a mechano-sorptive creep element shown in Fig. 4.

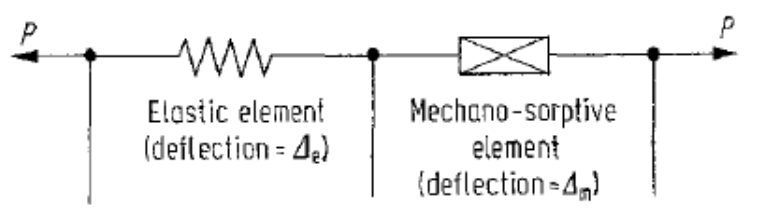

Fig. 4. The mechanical model for mechano-sorptive effect [7]

According to Fig 4, total deflection $\Delta$ of a wood beam was assumed to be the sum of an elastic component $\Delta_{e}$ and a mechano-sorptive component $\Delta_{\mathrm{m}}$ as follows.

$$
\begin{aligned}
& \Delta=\Delta_{e}+\Delta_{m} \\
& \Delta_{e}=K P \\
& -\frac{d \Delta_{m}}{d m}=P . f(m)
\end{aligned}
$$

where $P$ : load parameter, $K$ : constanta, $m$ : moisture content and $f(m)$ : a function of moisture content.

Ranta-Maunus [8] developed a generalized viscoelastic model for wood that includes moisture changes. In the one dimensional (1D) case the constitutive equation may then be written in the form

$$
\begin{aligned}
& \varepsilon(t)=\int_{0}^{t} J(t-\tau) d \sigma(\tau) \\
& \left.+\int_{0}^{t} K(t-\tau) \sigma(t)+L(t-\tau)(\sigma(t)-\sigma(\tau))(u(t)-u(\tau))\right) d u(\tau)
\end{aligned}
$$

where $\varepsilon$ : strain, $\sigma$ : stress, u: moisture content, $J$ : viscoelastic compliance, $K$, and $L$ are kernel functions describing the mechano-sorptive creep behavior and $t$ and $\tau$ are time variables. In Equation (9), the material is assumed to be reduced to time $t=0$. Different values of $K$ during absorption and desorption are important to describe mechano-sorptive creep.

Fridley et al. [9] had been modified four element model (Burger model), where a mechano-sorptive element is added to this model to account for observed mechanosorptive strain (Fig. 5).

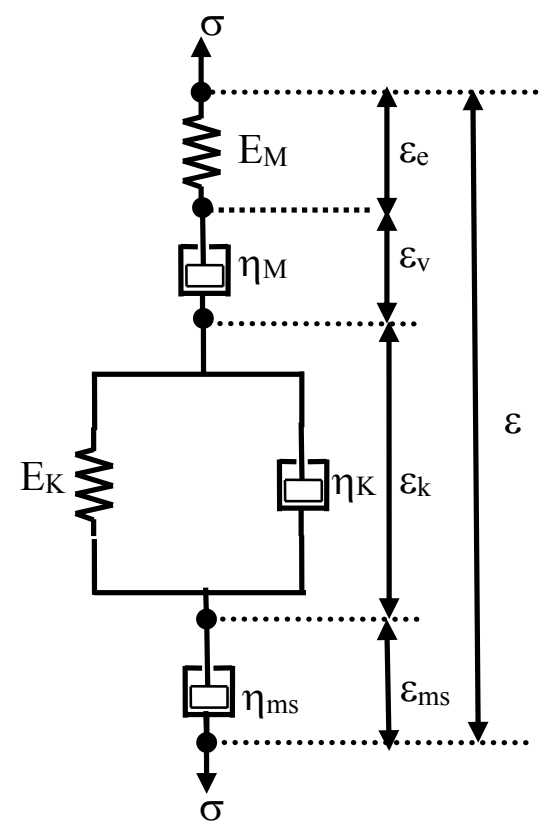

Fig. 5. Modified Burger Model with Mechano-sorptive Element [9]

The mechano-sorptive element is assumed to have a viscous parameter defined as a function rate of change moisture content as follows:

$\eta_{m s}=\frac{\eta_{m s}^{\prime}}{|\dot{\omega}|}$

where $\eta_{\text {ms }}$ : viscosity of the mechano-sorptive element; $\eta$ 'ms: constanta with units force per unit area; and $\dot{\omega}$ : rate of change moisture content. The rate of mechanosorptive strain $\left(\dot{\varepsilon}_{m s}\right)$ defined as

$\dot{\varepsilon}_{m s}=\frac{\sigma}{\eta_{m s}}$

If the average moisture content of the specimen after a sudden change in the surrounding environment is assumed

$\omega\left(t_{\omega}\right)=\omega_{e}+\left(\omega_{i}-\omega_{e}\right) \exp \left(-B_{\omega} t_{\omega}\right)$

The derivative of equation (12) to time is

$\dot{\omega}\left(t_{\omega}\right)=B_{\omega}\left(\omega_{e}-\omega_{i}\right) \exp \left(-B_{\omega} t_{\omega}\right)$ 
where $\omega\left(t_{\omega}\right)$ : average moisture content at a time $t_{\omega}$ following the environmental change; $\omega_{\mathrm{e}}$ : equilibrium moisture content in a new environment; $\omega_{\mathrm{i}}$ : initial moisture content in the original environment; and $\mathrm{B} \omega$ : constanta associated with the time required to achieve moisture equilibrium. The value of the $B_{\omega}$ is determined from curve fitting the relationship between time and moisture content, as an exponential function. For a constant applied load and changing moisture condition, the total mechano-sorptive strain is :

$$
\varepsilon_{m s}=\frac{\sigma}{\mu_{m s}^{\prime}}|\Delta \omega|\left\{1-\exp \left(-B_{\omega} t_{\omega}\right\}\right.
$$

where, $\Delta \omega=\omega_{\mathrm{e}}-\omega_{\mathrm{i}} ; \eta^{\prime}$ ms mechano-sorptive constanta can be estimated using an iterative best-fit procedure from experimental data. So, the total strain of material when subjected to constant applied load and moisture content variation at a time $\mathrm{t}$ is,

$$
\varepsilon(t)=\varepsilon_{e}+\varepsilon_{k}+\varepsilon_{m s}
$$

\subsection{Boltzmann Superposition Principle Model}

Boltzmann Superposition Principle Model or commonly referred to as integral representation can explain the relationship of stress-strain that is affected by time. The advantage of using this method is that it can be used more flexibly to model creep resulting from a constant step loading. If on a creep test, a gradual load is given where $\sigma_{0}$ is given for $\zeta_{1}$, then the load is increased by $\sigma_{1}$ for $\zeta_{2}$ and so on (Fig. 6), then $\varepsilon(\mathrm{t})$ can be determined by equation (16).

$$
\varepsilon(t)=\sum \varepsilon\left(\sigma_{0}, \xi_{1}\right)+\varepsilon\left(\Delta \sigma_{1}, \xi_{2}\right)+\ldots . . \varepsilon\left(\Delta \sigma_{i}, \xi_{i}\right)(16)
$$
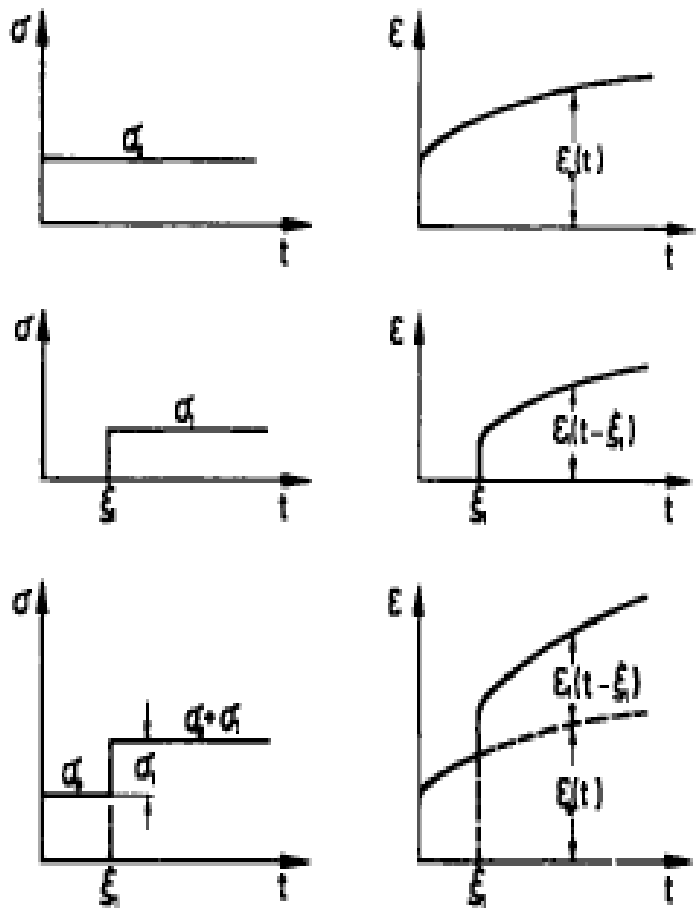

\section{Power Law Model}

Modelling the time-dependent behavior of gluedlaminated bamboo can be expressed empirical mathematical equations. One of the most successfully descriptions for creep in the viscoelastic material under constant relative humidity and temperature is the power law model, of the general form $[6,10]$

$$
\varepsilon(t)=\varepsilon_{0}+a t^{m}
$$

where $\varepsilon(\mathrm{t})$ : time-dependent strain, $\varepsilon_{0}$ : instantaneous strain, $\mathrm{a}$ and $\mathrm{m}$ are material constants can be determined with curve fitting experiment data, and t: elapsed time. The empirical equation above can adequate to describe a secondary stage, nonlinear creep behavior of the viscoelastic material, and easier than using other models.

\section{Finite Element Model}

Because of mathematical difficulties, few real problems in viscoelasticity have an analytical solution. As in many other areas of science, the use of numerical analyses and digital computers had a great impact in this field. Procedures based on techniques like Finite Element can provide analysis for structures made of linear and nonlinear viscoelastic materials. In part, these numerical procedures by using FEA program ABAQUS are described.

Modelling creep behavior of viscoelastic linear material on the FEA program ABAQUS, can be modeled as a prony series elements Maxwell models, plus a single elastic element $\mathrm{G}_{\infty}$ (Fig. 7).

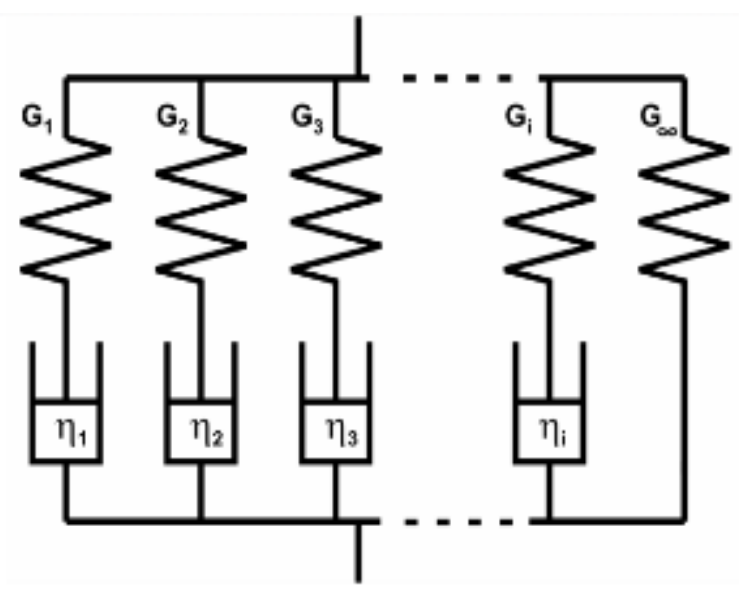

Fig. 7. Prony Series Elements Maxwell Model [11]

In the FEA program ABAQUS the prony series can be written with shear modulus $(G)$ as follows:

$$
G(t)=G_{\infty}+\left(\sum_{i=1}^{n} g_{i} G_{0} e^{\left(-t / \tau_{i}\right)}\right)
$$

where

Fig. 6. Bolztmann Superposition Principle Model [6] 
t: time, $\tau_{\mathrm{i}}=\eta_{\mathrm{i}} /$ Ei: relaxation time, $G_{0}=\frac{E}{2(1+v)}$ : initial shear modulus, $g_{i}=G_{i} / G_{0}$, at $\mathrm{t}=0$, $G_{\infty}=G_{0}\left(1-\sum_{i=1}^{n} g_{i}\right)$ so the prony series can be written:

$$
G(t)=G_{0}\left(1-\sum_{i=1}^{n} g_{i}\right)+\left(\sum_{i=1}^{n} g_{i} G_{0} e^{\left(-t / \tau_{i}\right)}\right)
$$

Kon and Yuan [12]; Ngudiyono et al. [3] by using Laplace Transformation method for converting the Burger Model to Prony Series in FEA program ABAQUS as follows

$$
G(t)=G_{\infty}+\left(\sum_{i=1}^{n} G_{i} G_{0} e^{\left(-t / \tau_{i}\right)}\right)
$$

If $\mathrm{n}=2$ so,

$$
G(t)=G_{\infty}+G_{1} e^{\left(-t / \tau_{i}\right)}+G_{2} e^{\left(-t / \tau_{2}\right)}
$$

where,

$$
\begin{aligned}
& G_{\infty}=0, G_{1}=\frac{G_{M}}{(\alpha-\beta)}\left(\frac{G_{K}}{\eta^{\prime}{ }_{K}}-\beta\right), \\
& G_{2}=\frac{G_{M}}{(\alpha-\beta)}\left(\alpha-\frac{G_{K}}{\eta^{\prime}{ }_{K}}\right), \tau_{1}=\frac{1}{\beta}, \tau_{2}=\frac{1}{\alpha}
\end{aligned}
$$

If

$$
\begin{aligned}
& g(t)=\frac{G(t)}{G_{0}} \\
& G(t)=G_{\infty}+G_{0}\left(g_{1} e^{\left(-t / \tau_{i}\right)}+g_{2} e^{\left(-t / \tau_{2}\right)}\right)
\end{aligned}
$$

where

$G_{0}=G_{M}, g_{1}=\frac{1}{(\alpha-\beta)}\left(\frac{G_{K}}{\eta_{K}^{\prime}}-\beta\right), g_{2}=\frac{1}{(\alpha-\beta)}\left(\alpha-\frac{G_{K}}{\eta_{K}^{\prime}}\right)$ $E_{M}, \mu_{M}, g_{1}, g_{2}, \tau_{1}, \tau_{2}$ is a Burger model parameter that can be used in the FEA program ABAQUS.

The behavior of the viscoelastic material in FEA program ABAQUS can also be modeled using the power law function which involves two variables, i.e., constant applied load $(\sigma)$ and time $(\mathrm{t})$. The power law approach is more effective than the classical mathematical approach (such as Maxwell, Kelvin, Burger, and others). The power law function is appropriate to explain nonlinear behavior. The power law equation is expressed in the rate of creep $\left(\dot{\varepsilon}_{c r}\right)$ as follows,

$\dot{\varepsilon}_{c r}=A \sigma^{n} t^{m}$

If equation (23) is integrated with time $(\mathrm{t})$, then the creep strain $\left(\varepsilon_{\mathrm{cr}}\right)$ is,

$\varepsilon_{c r}=\frac{A}{m+1} \sigma^{n} t^{m+1}$

where $\mathrm{A}, \mathrm{n}$, and $\mathrm{m}$ creep parameters can be obtained from the curve fitting of the creep test experimental data. In FEA program ABAQUS the value of $A$ and $n$ is greater than $0(\mathrm{~A}, \mathrm{n}>0)$ while the $\mathrm{m}$ value is more than 1 and less than or equal to $0(-1<\mathrm{m} \leq 0)$.

For the creep model of anisotropic or orthotropic material, the potential option is used to define the anisotropic or orthotropic stress creep ratio $R_{11}, R_{22}, R_{33}$, $\mathrm{R}_{12}, \mathrm{R}_{13}, \mathrm{R}_{23}$ where:

$R_{11}=\frac{\sigma_{11}}{\widetilde{q}}, R_{22}=\frac{\sigma_{22}}{\widetilde{q}}, R_{33}=\frac{\sigma_{33}}{\widetilde{q}}$,

$R_{12}=\frac{\sigma_{12}}{\tilde{q} / \sqrt{3}}, R_{13}=\frac{\sigma_{13}}{\tilde{q} / \sqrt{3}}, R_{23}=\frac{\sigma_{23}}{\tilde{q} / \sqrt{3}}$

$\widetilde{q}=$ Hill's stress equivalent

If the constitutive models are not available in the FEA program, the user is given the opportunity to add a constitutive model by creating subroutines. UMAT and DFLUX are subroutines to define a constitutive model of viscoelastic material for predicting creep behavior.

Mirianon et al. [13] had been using a viscoelastic and mechano-sorptive subroutine for time-dependent analysis that implemented into the user subroutine UMAT and DFLUX to define the rheological model and the flow of moisture on the surface of the wood. In this model is characterized by five deformation mechanisms (Fig. 8) which provide an additive decomposition of the strain. The time-dependent analysis can be solved by using an incremental analysis in time which takes into account the coupling of moisture changes and stresses. At the time $t=t_{n}$ the solution in terms of strain, stress, and moisture is assumed to be known, while solution at the time $t=t_{n+1}$ is determined. The total strain can be considered as composed of several parts which are related to different mechanisms acting in series:

$\varepsilon=\varepsilon^{e}+\varepsilon^{u}+\varepsilon^{v e}+\varepsilon^{m s}+\varepsilon^{m s(i r r)}$

where $\varepsilon$ : total strain, $\varepsilon^{e}$ : elastic strain, $\varepsilon^{u}$ : hygroexpansion strain, $\varepsilon^{\mathrm{ve}}$ :total viscoelastic strain, $\varepsilon^{\mathrm{ms}}$ : recoverable mechano-sorptive strain, and $\varepsilon^{\mathrm{ms}(\mathrm{irr})}$ : irrecoverable mechanosorptive strain. Equation (25) can be rewritten in terms of finite increments as follows:

$\Delta \varepsilon^{e}+\Delta \varepsilon^{v e}+\Delta \varepsilon^{m s}=\Delta \varepsilon-\Delta \varepsilon^{u}-\Delta \varepsilon^{m s(i r r)}$

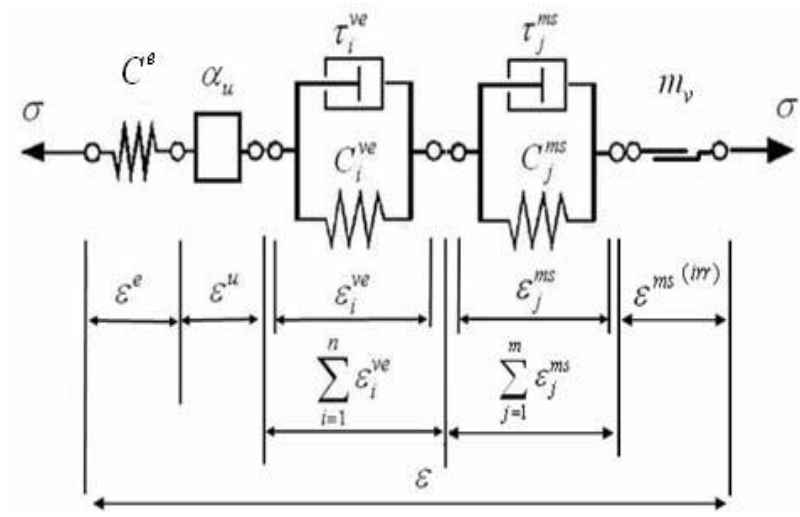

Fig. 8. Scheme 3D of the rheological model [13] 


\section{Modelling of Glued-Laminated Bamboo Structures with FEA Program ABAQUS}

Li and Xiao [14] had been used Burger model for compression and tensile one dimension (1D) creep analysis of glued-laminated bamboo, without considering the effect of humidity condition and orthotropic properties material. Currently, there is no readymade glued-laminated bamboo model in FEA program ABAQUS for time-dependent analysis, but there are ways to create your own material models using subroutines. In the present study, it is necessary to use the UMAT and DFLUX subroutine to define the rheological model and the flow of moisture on the surface of the glued-laminated bamboo. UMAT calculates the stress increment and the Jacobian matrix for each time increment. DFLUX calculates the flow of moisture between air and glued-laminated bamboo surfaces. The following scheme (Fig. 9) describes the modelling and calculating processes used for modelling glued-laminated bamboo.

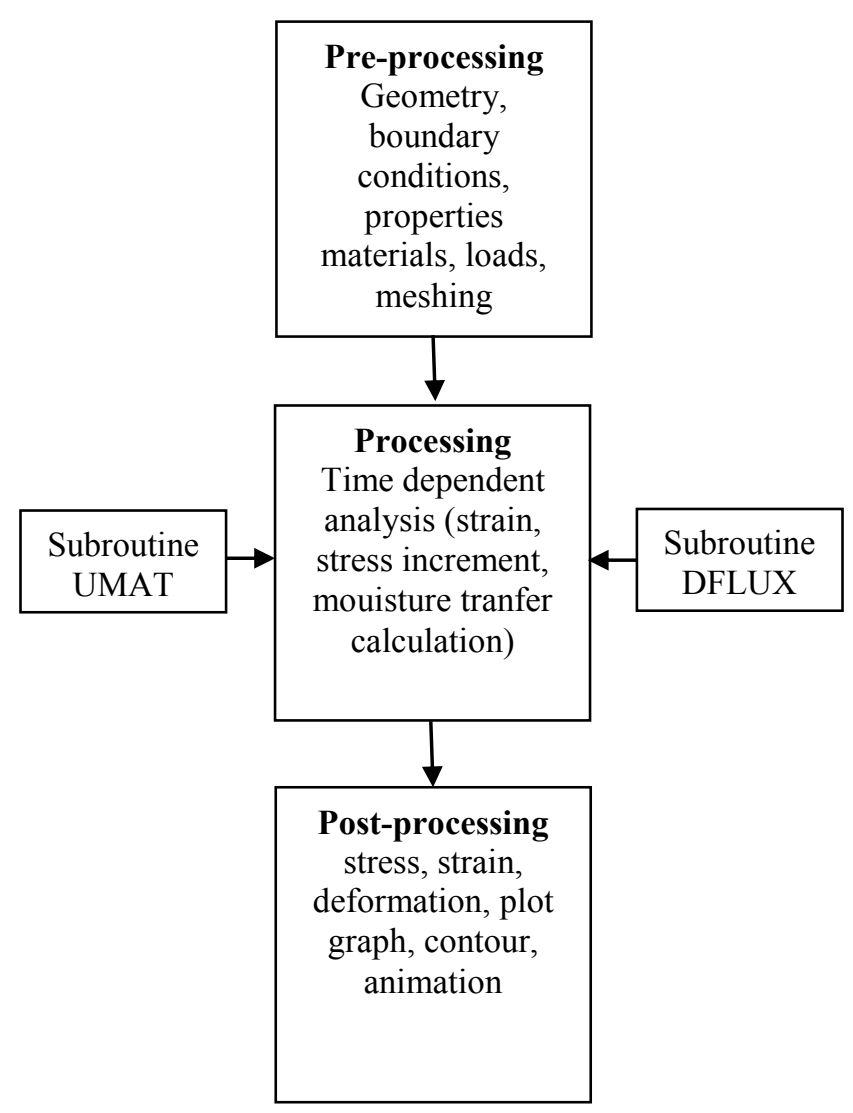

Fig. 9. Scheme modelling glued-laminated bamboo with FEA Program ABAQUS

\section{Conclusions}

There are several models to model creep behavior viscoelastic material. The differential operator (mechanical model, i.e., Maxwell, Kelvin, Burger model), the integral representation (Boltzmann Superposition Principle Model), Power Law and Finite Element Model. Modified mechanical models (Maxwell, Burger model) by adding mechano-shortive elements can be used to predict creep behavior of viscoelastic materials such as glued-laminated bamboo due to the variable relative humidity effects. The power law approach is more effective than the classical mathematical approach (such as Maxwell, Kelvin, Burger, and others) and can describe nonlinear creep behavior viscoelastic material. The time-dependent analysis model for the long-term behavior of gluedlaminated bamboo under constant loading and moisture variables can be developed with finite element models using FEA program ABAQUS. The rheological model is implemented with the UMAT subroutine, and moisture transfer is implemented in the DFLUX subroutine.

The authors of this manuscript would like thank to the Ministry of Research, Technology and the Higher Education Republic of Indonesia which has funded the Research Program Doctoral Dissertation with contract No.717/ UN18.L1 / PP / 2018.

\section{References}

1. Ni L., Zhang X., Liu H., Sun Z., Song G., Yang L., Jiang Z. Manufacture and Mechanical Properties of Glued Bamboo Laminates, Glued Bamboo Lumber. BioResources 11(2), pp 4459 - 4471, 2016

2. Sharma B., Gatoo A., Bock M., Ramage M. Engineered Bamboo for Structural Applications. Construction and Building Material 81, pp. 66-73, 2015

3. Ngudiyono, Suhendro B., Awaludin A., Triwiyono A. Finite Element Modelling of Creep GluedLaminated Bamboo, Proceeding of $2^{\text {nd }}$ The 2nd International Conference on Science and Technology (ICST) University of Mataram and University of Malaya, 2017

4. Awaludin A., Ngudiyono, Basuki A., Creep Properties of Walikukun (Schouthenia ovata) Timber Beams. Civil Engineering Dimension, 18 (2), pp. 78-84, 2016

5. Gottron J., Harries K. A., \&Xu Q. Creep Behavior of Bamboo.Construction and Building Material, pp. 79-88, 2014

6. Findley M. N., Lai J. S., \& Onaran K., Creep and Relaxation of Nonlinear Viscoelastic Material with Introduction to Linear Viscoelastic, Dover Publication, Inc. New York, 1976

7. Leicester, R. H., A Rheological Model for Mechano-sorptive Deflections of Beams. Wood Science and Technology, 5, pp. 211-220, 1971 
8. Ranta-Maunus A., The Viscoelasticity of Wood at Varying Moisture Content, Wood Science and Technology, 9, pp. 189-205, 1975

9. Fidley, K. J., Tang, R. C., Soltis, L. A., Creep Behavior Model for Structural Lumber, Journal of Structural Engineering, 118, 8, August, pp. 2261 2277, 1992

10. Dinwoodie, J. M., Timber: Its nature and behavior, Published by E \& F Spon, London and New York, 2000

11. Abaqus Version 6.4. Abaqus/CAE User's Manual. Pawtucket, Rhode Island, USA, 2003

12. Kong J., \&Yuan J., Application of Linear Viscoelastic Differential Constitutive Equation in ABAQUS. International Conference On Computer Design And Applications (ICCDA), 2010

13. Mirianon F, Fortino S., \& Toratti T., A method to model wood by using ABAQUS finite element software, Part 1: Constitutive model and computational details, VTT Publications 687, Espoo, 2008

14. Li, L., and Xiao, Y., Creep Behavior of Glubam and CFRP-Enhanced Glubam Beams, Journal of Compositers for Contruction, 10, Juni, pp 1-11, 2015. 